\title{
STUDY OF THE KINETICS AND MECHANISMS OF THERMAL DECOMPOSITION OF MOROCCAN TARFAYA OIL SHALE AND ITS KEROGEN
}

\author{
A. ABOULKAS ${ }^{*(a, b)}, K_{\text {. EL HARFI }}^{(a, b)}$
}

(a) Laboratoire de Recherche sur la Réactivités des Matériaux et l'Optimisation des Procédés «REMATOP», Département de chimie, Faculté des Sciences Semlalia Université Cadi Ayyad, BP 2390, 40001 Marrakech, Maroc

(b) Département de chimie, Faculté polydisciplinaire de Béni-Mellal Université Sultan Moulay Slimane, BP 592, 23000 Béni-Mellal, Maroc

In this research, thermal characteristics and kinetic parameters of Tarfaya oil shale and its kerogen samples were determined by thermogravimetry (TG/DTG) under non-isothermal heating conditions. The pyrolysis experiments were performed increasing the temperature up to $1273 \mathrm{~K}$ at heating rates of 2 , 10,20 and $50 \mathrm{~K} / \mathrm{min}$ in an inert atmosphere of nitrogen. The mass loss curve showed that pyrolysis of kerogen took place mainly in the range of 433-873 K. At higher temperatures there was a significant mass loss due to decomposition of mineral matter. It has been found that for oil shale and its kerogen analysed using the TG/DTG, the increase in the heating rate shifts the maximum rate loss to a higher temperature. Kissinger-Akahira-Sunose, Friedman, FlynnWall-Ozawa and Coats-Redfern methods were used to determine the apparent activation energies of materials' degradation. The analyses of the process mechanism by the methods of Criado et al. and Coats-Redfern showed that the most probable model for the pyrolysis process of organic matter of oil shale agrees with the diffusion model (D4 mechanism), and the thermal degradation process of isolated kerogen corresponds to a mechanism involving a simple $n$ order model (F1 mechanism). The apparent activation energies for the organic matter of oil shale and isolated kerogen were 80-87 and 69-76 kJ/mol, respectively. A single kinetic expression is valid over the temperature range of kerogen pyrolysis between 433 and $873 \mathrm{~K}$. In addition, the results indicate that the removal of mineral matter affected the kinetics and mechanism established for kerogen in oil shale.

\footnotetext{
*Corresponding author: e-mail a.aboulkas@ucam.ac.ma
} 


\section{Introduction}

World reserves of conventional fossil fuels such as petroleum, natural gas and coal are finite. The supply of energy has become a worldwide problem in recent decades. Many countries have attempted to diversify their potential energy sources in order to cope with oil price increases and their effect on the economy. So, there are a plenty of researches into alternative sources of conventional fossil fuels. Oil shale represents an enormous potential as a substitute.

In Morocco, $90 \%$ of the energy consumed is dependent on imported oil. Thus, an intensive programme was commenced for the mobilization of indigenous energy sources, especially local oil shales. Morocco is very rich in Upper Cretaceous oil shale deposits, the main sites are located at Timahdit (Middle Atlas Mountains) and Tarfaya (South Morocco) [1]. The oil shale deposits in Morocco represent about 15\% of known oil shale resources in the world [2].

Thermogravimetric analysis (TGA) of oil shale samples has been extensively used as a means of determining pyrolysis characteristics and also to determine kinetic parameters [3-8]. Non-isothermal thermogravimetry (TG) has been applied in the study of the kinetics of thermal decomposition of Green River oil shale kerogen [3]. It was shown that the decomposition process involves two consecutive first order reactions. Kerogen decomposes to intermediate bitumen and the pyrolytic bitumen further decomposes into oil, gas and carbonaceous residue. Torrente and Galan [4] studied the kinetics of thermal decomposition of oil shale from Puertollano (Spain) by isothermal and non-isothermal thermogravimetry analyses. They reported that decomposition of the shale could be described by overall first-order kinetics. Among the three parameters used in the calculation of the kinetic parameters, the integral method yields lower deviation and, hence, provides a better fit of the data. Kök [5] studied the thermal behavior of Seyitomer oil shale by thermogravimetry (TG/DTG) and differential scanning calorimetry (DSC). It was reported that the decomposition took place in more than one reaction region where the apparent activation energies of the first region are higher. Higher heating rates resulted in higher reaction temperatures. It was shown that the decomposition process of the oil shale could be described by a pseudo first order reaction. Karabakan and Yurum [6] investigated the effect of mineral matrix of oil shales. They found out that pyrolysis reactions were catalyzed by alkaline earth metal cations in carbonates and inhibited by silicates. The inhibition effect of the silicates seemed to be greater than the catalytic effect of the carbonates in the pyrolysis reactions of the original Göynük and Green River oil shales. Jaber and Probert [7] studied oil shale samples using a thermogravimetric analyzer. The integral method was used in the analysis of TG data in order to determine the pyrolysis kinetics. It was observed that the magnitude of the total mass loss was mainly dependent on the final temperature, as well as, to a lesser extent, on the heating rate 
employed. Williams and Ahmad [8] studied oil shale samples in a thermogravimetric analyzer in relation to heating rate and temperature using nonisothermal and isothermal analysis respectively. The main region of mass loss corresponding to hydrocarbon oil and gas release was between 473-893 K, and a significant mass loss at higher temperatures was attributed to carbonate decomposition.

The present investigation is an experimental study on Tarfaya oil shale and its kerogen samples using a TGA apparatus under non-isothermal conditions. The objective was to investigate the effects of mineral matter of the oil shale on the kinetic parameters of kerogen conversion. For this reason, kinetic models are proposed which allow a good correlation of the results obtained.

\section{Theoretical approach}

The application of dynamic TG methods holds great promise as a tool for unravelling the mechanisms of physical and chemical processes that occur during solids' degradation. In this paper, five methods have been used to analyze the non-isothermal kinetics of Tarfaya oil shale and its kerogen. The pyrolysis process may be represented by the following reaction scheme:

$$
A_{(\text {solid })} \rightarrow B_{(\text {Solid) }}+C_{(\text {Volatile })}
$$

The rate of conversion, $\frac{\mathrm{d} x}{\mathrm{~d} t}$ for TG experiment at constant rate of temperature change, $\beta=\mathrm{d} T / \mathrm{d} t$ may be expressed by

$$
\frac{\mathrm{d} x}{\mathrm{~d} t}=\beta \frac{\mathrm{d} x}{\mathrm{~d} T}=K(T) f(x),
$$

where $x$ is the degree of advance, $f(x)$ and $K(T)$ are functions of conversion and temperature, respectively.

$K(T)$, the temperature dependence of the rate of weight loss, is often modeled successfully by the Arrhenius equation

$$
K(T)=A \exp \left(-\frac{E}{R T}\right),
$$

where $E$ is the apparent activation energy, $A$ the pre-exponential factor and $R$ the gas constant.

\section{Kissinger-Akahira-Sunose method (KAS method) $[9,10]$}

The standard Eq. (1) can be shown as follows:

$$
\frac{\mathrm{d} x}{f(x)}=\frac{A}{\beta} \exp \left(-\frac{E}{R T}\right) \mathrm{d} T
$$


which is integrated with the initial condition of $x=0$ at $T=T_{0}$ to obtain the following expression:

$$
g(x)=\int_{0}^{x} \frac{\mathrm{d} x}{f(x)}=\frac{A}{\beta} \int_{T_{0}}^{T} \exp \left(-\frac{E}{R T}\right) \mathrm{d} T=\frac{A E}{\beta R} p\left(\frac{E}{R T}\right) .
$$

Since, essentially the technique assumes that the $A, f(x)$ and $E$ are independent of $T$, while $A$ and $E$ are independent of $x$.

The KAS method is based on the Coats-Redfern approximation [11] and relationship (4):

$$
\ln \frac{\beta}{T^{2}}=\ln \frac{A R}{E g(x)}-\frac{E}{R T} .
$$

Thus, the plot $\ln \beta / T^{2}$ vs. $1 / T$ for a constant value of $x$ should be a straight line whose slope can be used to evaluate the apparent activation energy.

\section{Friedman method [12]}

This method is a differential isoconversional method and is directly based on Eq. (1) whose logarithm is

$$
\ln \left(\frac{\mathrm{d} x}{\mathrm{~d} t}\right)=\ln \left(\beta \frac{\mathrm{d} x}{\mathrm{~d} T}\right)=\ln [A f(x)]-\frac{E}{R T} .
$$

From this equation, it is easy to obtain values for $E$ over a wide range of conversions by plotting $\ln (\beta \mathrm{d} x / \mathrm{d} T)$ against $1 / T$ for a constant $x$ value.

\section{Flynn-Wall-Ozawa method [13, 14]}

This method is derived from integral isoconversional method. Using Doyle's approximation [15] for the integral which allows $\ln p(E / R T) \cong$ $-5.331-1.052 E / R T$

$$
\ln \beta=\ln \frac{A E}{R g(x)}-5.331-1.052 \frac{E}{R T} .
$$

Thus, for $x=$ const., the plot $\ln \beta$ vs. $1 / T$, obtained from thermograms recorded at several heating rates, should be a straight line whose slope can be used to evaluate the apparent activation energy.

\section{Coats-Redfern method [11]}

Coats-Redfern method is also an integral method, and it involves the thermal degradation mechanism. Using an asymptotic approximation for the resolution of Eq. (4) $(2 R T / E\langle\langle 1)$, the following equation can be obtained: 


$$
\ln \frac{g(x)}{T^{2}}=\ln \frac{A R}{\beta E}-\frac{E}{R T} .
$$

\section{Criado method [16]}

If the value of the apparent activation energy is known, the kinetic model of the process can be determined by this method. Combining Eq. (1) with Eq. (8), the following equation is obtained:

$$
\frac{Z(x)}{Z(0.5)}=\frac{f(x) g(x)}{f(0.5) g(0.5)}=\left(\frac{T_{x}}{T_{0.5}}\right)^{2} \frac{(\mathrm{d} x / \mathrm{d} t)_{x}}{(\mathrm{~d} x / \mathrm{d} t)_{0.5}},
$$

where 0.5 refers to the conversion in $x=0.5$.

The left side of Eq. (9) $(f(x) g(x)) /(f(0.5) g(0.5))$ is a reduced theoretical curve, which is characteristic of each reaction mechanism, whereas the right side of the equation associated with the reduced rate can be obtained from experimental data. A comparison of both sides of Eq. (9) tells us which kinetic model describes an experimental reactive process. Table 1 indicates the algebraic expressions of $f(x)$ and $g(x)$ for the kinetic models used.

Table 2 shows the approximated equations of the five kinetic methods used for the calculation of apparent activation energy and mechanisms

Table 1. Algebraic expressions of functions of the most common reaction mechanisms operating in solid-phase reactions

\begin{tabular}{|l|c|c|}
\hline \multicolumn{1}{|c|}{ Mechanism } & $f(x)$ & $g(x)$ \\
\hline Power law (P2) & $2 x^{1 / 2}$ & $x^{1 / 2}$ \\
Power law (P3) & $3 x^{2 / 3}$ & $x^{1 / 3}$ \\
Power law (P4) & $4 x^{3 / 4}$ & $x^{1 / 4}$ \\
Avarami-Erofe'ev (A2) & $2(1-x)[-\ln (1-x)]^{1 / 2}$ & {$[-\ln (1-x)]^{1 / 2}$} \\
Avarami-Erofe'ev (A3) & $3(1-x)[-\ln (1-x)]^{2 / 3}$ & {$[-\ln (1-x)]^{1 / 3}$} \\
Avarami-Erofe'ev (A4) & $4(1-x)[-\ln (1-x)]^{3 / 4}$ & {$[-\ln (1-x)]^{1 / 4}$} \\
Contracting area (R2) & $2(1-x)^{1 / 2}$ & {$\left[1-(1-x)^{1 / 2}\right]$} \\
Contracting volume (R3) & $3(1-x)^{2 / 3}$ & {$\left[1-(1-x)^{1 / 3}\right]$} \\
One-dimensional diffusion (D1) & $1 / 2 x$ & $x^{2}$ \\
Two-dimensional diffusion (D2) & {$[-\ln (1-x)]^{-1}$} & {$[(1-x) \ln (1-x)]+x$} \\
Three- dimensional diffusion, & $3(1-x)^{2 / 3} /\left[2\left(1-(1-x)^{1 / 3}\right)\right]$ & {$\left[1-(1-x)^{1 / 3}\right]^{2}$} \\
Jander (D3) & $3 / 2\left((1-x)^{-1 / 3}-1\right)$ & $1-(2 x / 3)-(1-x)^{2 / 3}$ \\
Ginstling-Brounshtein (D4) & $(1-x)$ & $-\ln (1-x)$ \\
First-order (F1) & $(1-x)^{2}$ & $(1-x)^{-1}-1$ \\
Second-order (F2) & $(1-x)^{3}$ & {$\left[(1-x)^{-2}-1\right] / 2$} \\
Third-order (F3) & & \\
\hline
\end{tabular}


Table 2. Approximated equations of the kinetic methods used for calculation of apparent activation energy values and mechanisms

\begin{tabular}{|l|l|}
\hline \multicolumn{1}{|c|}{ Method } & \multicolumn{1}{|c|}{ Approximated equation } \\
\hline Kissinger-Akahira-Sunose [9, 10] & $\ln \frac{\beta}{T^{2}}=\ln \frac{A R}{E g(x)}-\frac{E}{R T}$ \\
Friedman [12] & $\ln \left(\frac{d x}{d t}\right)=\ln \left(\beta \frac{d x}{d T}\right)=\ln [A f(x)]-\frac{E}{R T}$ \\
Flynn-Wall-Ozawa [13, 14] & $\ln \beta=\ln \frac{A E}{R g(x)}-5.331-1.052 \frac{E}{R T}$ \\
Coats-Redfern [11] & $\ln \frac{g(x)}{T^{2}}=\ln \frac{A R}{\beta E}-\frac{E}{R T}$ \\
Criado [16] & $\frac{Z(x)}{Z(0.5)}=\frac{f(x) g(x)}{f(0.5) g(0.5)}=\left(\frac{T_{x}}{T_{0.5}}\right)^{2} \frac{(d x / d t)_{x}}{(d x / d t)_{0.5}}$ \\
\hline
\end{tabular}

\section{Experimental}

\section{Materials}

Oil-shale deposits have been identified at ten localities in Morocco (Fig. 1), the most important of which are Upper Cretaceous marinates [17]. The two deposits that have been explored most extensively are the Timahdit and the Tarfaya deposits.

The oil shale used in this work originated from the Tarfaya deposit located in the south-western part of Morocco, near the border with Western Sahara. The oil shale averages $22 \mathrm{~m}$ in thickness, and its grade averages $62 \mathrm{l} / \mathrm{t}$. The total oil-shale resource is estimated at 86 billion tons within a $2500-\mathrm{km}^{2}$ area [2]. This deposit is divided into five lithologic zones $(\mathrm{P}, \mathrm{Q}, \mathrm{R}, \mathrm{S}$ and $\mathrm{T})$. Zone R with a thickness varying between 33 and $42 \mathrm{~m}$ is the richest in organics. This zone is divided into five different sub-zones (R0, R1, R2, R3 and R4). The highest amount of oil can be obtained from the sub-zone R3 (Fig. 2) which is therefore used in the experiments [2]. The results of the analysis of these samples are given in Table 3 . The organic matter belongs to Type II kerogen and covers a relatively wide range of maturity with $R_{0}=0.32 \pm 0.04 \%$ (vitrinite reflectance). Vitrinite reflectance $\left(R_{\mathrm{o}}\right)$ value is microscopically determined on the wood-derived maceral vitrinite. 


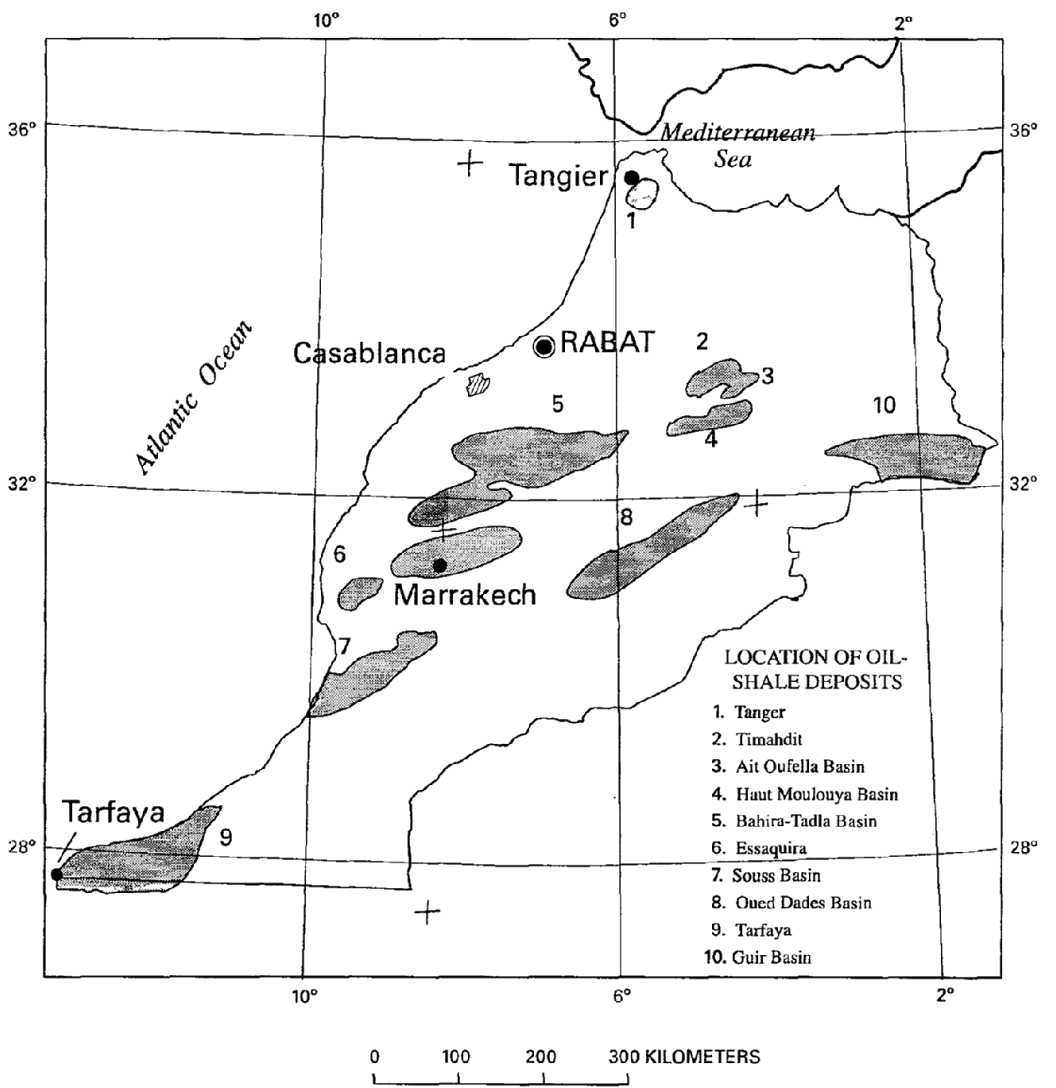

Fig. 1. Locations of oil-shale deposits in Morocco. From Bouchta ([17], Fig. 1).

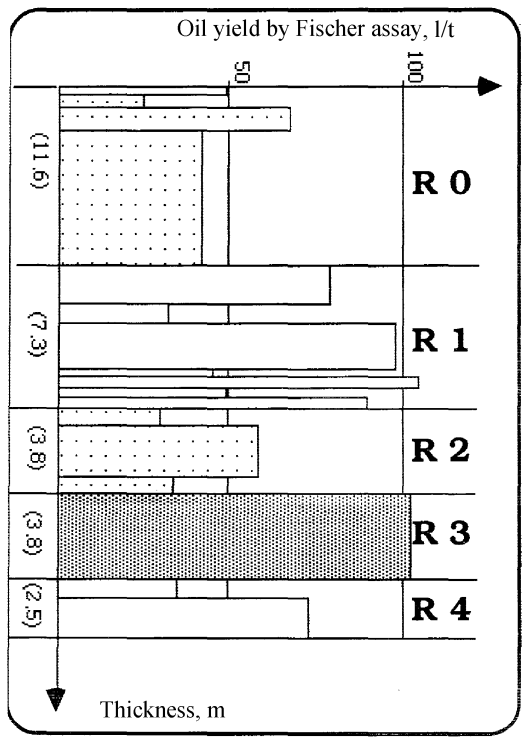

Fig. 2. Zone R of Tarfaya oil shale deposit. 
Table 3. Some average physicochemical characteristics of the Tarfaya oil shale

\begin{tabular}{|l|c|}
\hline Proximate analysis (wt.\%) & \\
Volatile matter & 40.09 \\
Ash & 52.83 \\
Moisture (as received) & 5.15 \\
Elemental analysis (wt.\%) & \\
C & 17.60 \\
H & 1.78 \\
N & 0.70 \\
S & 0.37 \\
Kerogen type & Type II \\
\hline
\end{tabular}

\section{Preparation of kerogen}

The finely ground samples of oil shale were treated with chloroform to extract the bitumen until the solvent in the Soxhlet arm becomes colourless. The bitumen-free $(\mathrm{BF})$ oil shale was then dried and weighed. It was subsequently attached with $\mathrm{HCl}\left(\mathrm{HCl} / \mathrm{H}_{2} \mathrm{O}=1: 2,343 \mathrm{~K}\right.$ under nitrogen) until no further carbon dioxide evolved. The residue was washed with hot distilled water until the silver nitrate test for chlorides was negative. The hydrochloric attack was repeated twice to eliminate all calcium products. The decarbonated oil shale was dried, washed with a mixture of $\mathrm{HCl} / \mathrm{HF}(1: 1)$ at $343 \mathrm{~K}$ under a nitrogen atmosphere. The silicate-free (SF) oil shale obtained in this step was then washed with hot distilled water. After drying SF oil shale, a saturated boric acid solution was added and the sample was stirred for $30 \mathrm{~min}$. Finally, the remaining brown solid was treated with $6 \mathrm{~N} \mathrm{HCl}$ and the kerogen was washed with hot distilled water to remove chlorides and dried overnight at $333 \mathrm{~K}$. Pyrite was removed by the method of density difference. The silicate-free oil shale was subjected to ultrasounds, at $313 \mathrm{~K}$ during $60 \mathrm{~min}$, followed by centrifugation using chloroform $\mathrm{CH}_{3} \mathrm{Cl}$ like a medium of suspension. In order to extract the maximum of the pyrite, this separation was carried out three times. The yields of the demineralization procedure of the oil shale are presented in Table 4.

\section{Table 4. Chemical composition of the $\mathbf{R}_{\mathbf{3}}$ sub-layer}

\begin{tabular}{|l|l|}
\hline \multicolumn{1}{|c|}{ Component } & \multicolumn{1}{c|}{ mass \% } \\
\hline Bitumen & 0.80 \\
Carbonate mineral & 70.00 \\
Silicate mineral & 10.00 \\
Pyrite & 1.00 \\
Kerogen & 17.00 \\
\hline
\end{tabular}




\section{Experimental techniques}

Raw oil shale and its isolated kerogen samples were subjected to thermogravimetric analysis (TGA) in an inert atmosphere of nitrogen. Rheometrix Scientific STA 1500 TGA analyzer was used to measure and record the sample mass change with temperature over the course of the pyrolysis reaction. Thermogravimetric curves were obtained at four different heating rates $(2,10,20$ and $50 \mathrm{~K} / \mathrm{min}$ ) between $300 \mathrm{~K}$ and $1273 \mathrm{~K}$; the precision of reported temperatures was estimated to be $\pm 2{ }^{\circ} \mathrm{C}$. Nitrogen gas was used as an inert purge gas to displace air in the pyrolysis zone, thus avoiding unwanted oxidation of the sample. Gas (flow rate of around $60 \mathrm{ml} / \mathrm{min}$ ) was fed to the system from a point below the sample, and a purge time of $60 \mathrm{~min}$ was applied (to be sure the air was eliminated from the system and the atmosphere is inert). The balance can hold a maximum of $45 \mathrm{mg}$; therefore, all sample amounts used in this study averaged approximately $20 \mathrm{mg}$. The reproducibility of the experiments is acceptable, and the experimental data presented in this paper corresponding to the different operating conditions are the mean values of runs carried out two or three times.

\section{Results and discussion}

\section{Thermogravimetric analysis}

Figures 3 and 4 show the weight loss (TG) and differential weight loss (DTG) curves of oil shale and isolated kerogen samples in relation to heating rate to the final temperature of $1273 \mathrm{~K}$. The curves demonstrate two or three stages in the mass-loss profile illustrated in the derivative curves.

The lower temperature region of mass loss of both samples, up to approximately $443 \mathrm{~K}$, has been attributed to the loss of moisture, loss of interlayer water from clay minerals and also to decomposition of mineral

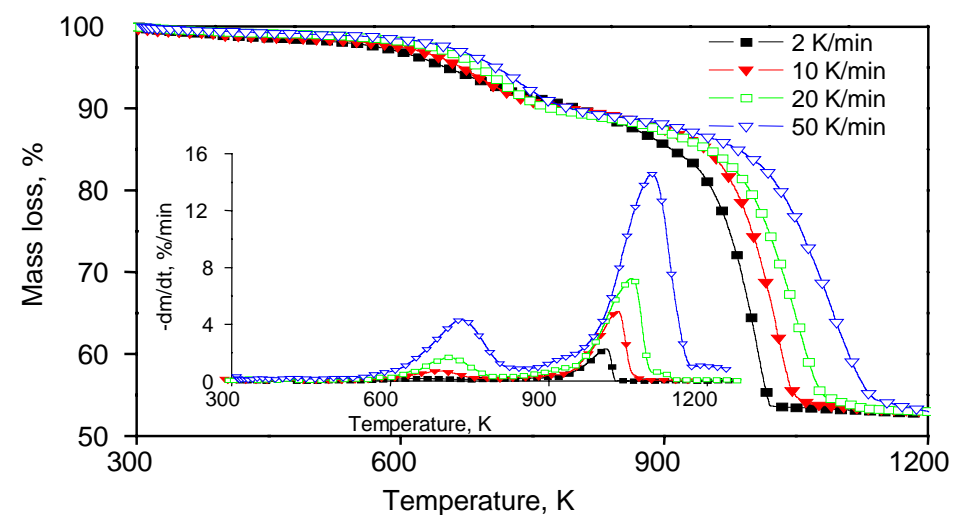

Fig. 3. TG curves of oil shale at different heating rates. Inset: corresponding DTG curves. 


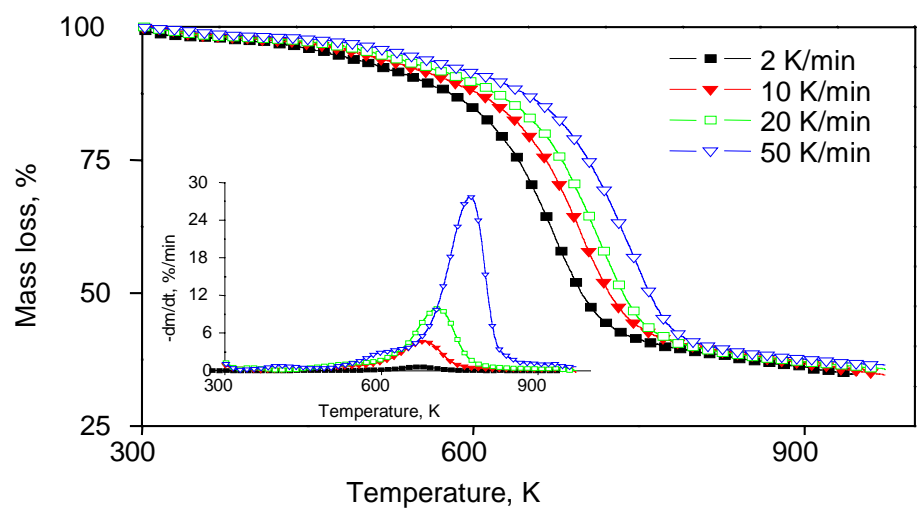

Fig. 4. TG curves of isolated kerogen at different heating rates. Inset: corresponding DTG curves.

nahcolite which is one of the minerals present in the raw shale [18]. Mass loss has also been attributed to physical changes, such as softening and molecular rearrangement associated with the release of gases in kerogen prior to its decomposition to bitumen which may occur as well [19]. Above all, in this stage the predominant cause of mass loss is simply moisture and it is less. Usually, the weight loss in this stage is considered the measure of water present in oil shale and isolated kerogen.

The stage of mass loss from about 433 to $873 \mathrm{~K}$ occurs on account of the hydrocarbon material. The oil shale and isolated kerogen exhibit an one-step thermal decomposition in the main mass loss area attributed to the formation of volatile hydrocarbons that occurs in the temperature range of 433-873 K. The one-step decomposition has also been observed by other workers for different oil shales, for example, for Huadian [20], Pakistan (Kark, Dharangi and Malgeen) [21] and Jordanian [7] oil shales. However, Turkish oil shale [22] and Kimmeridge oil shale [23] exhibit a two-stage thermal decomposition. Therefore, weather the decomposition is an one-stage or two-stage process, depends on the type of oil shale. Usually, decomposition of kerogen to oil, gas and char products is a two-stage process. First, decomposition of kerogen to pyrolytic bitumen occurs and, second, decomposition of bitumen to final products takes place. Though the curves show one-stage or two-stage decomposition process of oil shales, the mechanism of decomposition is a much more complex reaction involving a series of parallel reactions [23, 24].

Heating above $873 \mathrm{~K}$ caused decomposition of mineral matter at temperatures between 873 and $1200 \mathrm{~K}$ due to the presence of the carbonate and silicate minerals (only oil shale sample). The oil shale showed a high rate of mass loss in this range.

Table 5 shows the analysis of the TGA data in relation to heating rate in terms of the onset of mass loss of kerogen $\left(T_{\text {onset }}\right)$, the temperature where maximum devolatilisation occurs $\left(\mathrm{T}_{\max }\right)$ and the maximum rates $\left(\mathrm{R}_{\max }\right)$ of mass loss in the temperature range of $443-1200 \mathrm{~K}$. 
Table 5 shows that as the heating rate is increased, there was a lateral shift to higher temperatures for $T_{\text {onset, }}, T_{\max 1}$ and $T_{\max 2}$ for the both samples. The lateral shift is also illustrated in Figs. 3 and 4 for the DTG curves. The rate of mass loss also reflects the lateral shift with an increase in the rate, as the heating rate was increased from 2 to $50 \mathrm{~K} / \mathrm{min}$. The lateral shift to higher temperatures for the maximum region of mass loss has also been observed by other workers using TGA to investigate the pyrolysis of oil shales. For example, Gersten et al. [25] showed a lateral shift in the maximum rate of weight loss of about $38^{\circ} \mathrm{C}$ as the heating rate was increased from 5 to $50 \mathrm{~K} / \mathrm{min}$ for Israel oil shale. Kök [5] and Jaber and Probert [7, 19] also showed a lateral shift in the maximum rate of mass loss for the TGA of oilshale samples. This can be attributed to the variations in the rate of heat transfer with the change in the heating rate and the short exposure time to a particular temperature at higher heating rates [26], as well as the effect of the kinetics of decomposition [27]. Actually, at higher heating rates, the external surface of the shale particle will be hotter than its core. This would lead to reactions occurring inside the particle at lower temperatures, and the resultant products will leave and pass through the high-temperature region, hence secondary reactions ensue. The latters will reduce the yield of shale oil, the required product from the oil-shale pyrolysis process.

The data in Table 5 also indicate that $\mathrm{T}_{\text {onset }}$ and $\mathrm{T}_{\max 1}$ of isolated kerogen are inferior to those of organic matter of oil shale.

Table 5. Comparison of thermogravimetric data of oil shale and isolated kerogen samples

\begin{tabular}{|c|c|c|c|c|c|c|}
\hline Sample & $\begin{array}{c}\text { Heating rate, } \\
\mathrm{K} / \mathrm{min}\end{array}$ & \multicolumn{3}{|c|}{ Temperature, $\mathrm{K}$} & \multicolumn{2}{c|}{$\begin{array}{c}\text { Rate of mass loss, } \\
\text { mass } \% / \mathrm{min}\end{array}$} \\
\cline { 3 - 7 } & & $\mathrm{T}_{\text {onset }}$ & $\mathrm{T}_{\max 1}$ & $\mathrm{~T}_{\max 2}$ & $\mathrm{R}_{\max 1}$ & $\mathrm{R}_{\max 2}$ \\
\hline Oil shale & 2 & 537 & 664 & 1017 & 0.18 & 2.24 \\
& 10 & 580 & 687 & 1041 & 0.68 & 4.90 \\
& 20 & 602 & 716 & 1064 & 1.62 & 7.23 \\
& 50 & 626 & 733 & 1110 & 4.27 & 14.56 \\
Kerogen & 2 & 460 & 658 & - & 0.92 & - \\
& 10 & 478 & 676 & - & 4.65 & - \\
& 20 & 523 & 705 & - & 9.94 & - \\
& 50 & 570 & 724 & - & 27.77 & - \\
\hline
\end{tabular}

\section{Kinetics of thermal decomposition}

A TG study consists of performing a kinetic analysis which includes weight loss curves obtained at different heating rates in order to deduce the dependence of the kinetic parameters with the conversion. The KAS method has been firstly employed to analyse the TG data of oil shale and its kerogen. Eq. (5) has been used to obtain the apparent activation energy which can be calculated from the plot of $\ln \left(\beta / T^{2}\right)$ versus $1 / T$ fitting a straight line. The 
results are given in Table 6. The apparent activation energy of thermal degradation of oil shale and its kerogen are 80 and $69 \mathrm{~kJ} / \mathrm{mol}$, respectively.

Another derivative method used in this paper is Friedman's method, which is probably the most general of the derivative techniques. This method is based on the intercomparison of the rates of weight loss $\mathrm{d} x / \mathrm{d} t$ with different linear heating rates $\beta$ for a given fractional weight loss. Eq. (6) has been used to determine the values of apparent activation energies from plots of $\ln (\mathrm{d} x / \mathrm{d} t)$ versus $1 / T$ over a wide range of conversions. The calculated results are summarized in Table 7. Although the mean values of $E$ are 85 and $73 \mathrm{~kJ} / \mathrm{mol}$ for oil shale and kerogen, respectively.

The Flynn-Wall-Ozawa method is an integral method also being independent of the degradation mechanism. Eq. (7) has been used, and the apparent activation energy of degradation of the oil shale and its kerogen can

Table 6. Apparent activation energies of oil shale and isolated kerogen obtained by Kissinger-Akahira-Sunose method

\begin{tabular}{|c|c|c|c|}
\hline \multicolumn{2}{|c|}{ Oil shale } & \multicolumn{2}{|c|}{ Kerogen } \\
\hline $\mathrm{x}$ & $\begin{array}{c}\text { Activation energy, } \\
\mathrm{kJ} / \mathrm{mol}\end{array}$ & $\mathrm{x}$ & $\begin{array}{c}\text { Activation energy, } \\
\mathrm{kJ} / \mathrm{mol}\end{array}$ \\
\hline 0.04 & 91 & 0.1 & 66 \\
0.06 & 66 & 0.2 & 67 \\
0.08 & 64 & 0.3 & 73 \\
0.10 & 70 & 0.4 & 72 \\
0.12 & 81 & 0.5 & 70 \\
0.14 & 85 & 0.6 & 71 \\
0.16 & 83 & 0.7 & 70 \\
0.18 & 102 & 0.9 & 67 \\
& & & 65 \\
Mean & 80 & Mean & 69 \\
\hline
\end{tabular}

Table 7. Apparent activation energies of oil shale and isolated kerogen obtained by Friedman's method

\begin{tabular}{|c|c|c|c|}
\hline \multicolumn{2}{|c|}{ Oil shale } & \multicolumn{2}{c|}{ Kerogen } \\
\hline $\mathrm{x}$ & $\begin{array}{c}\text { Activation energy, } \\
\mathrm{kJ} / \mathrm{mol}\end{array}$ & $\mathrm{x}$ & $\begin{array}{c}\text { Activation energy, } \\
\mathrm{kJ} / \mathrm{mol}\end{array}$ \\
\hline 0.04 & 72 & 0.1 & 69 \\
0.06 & 81 & 0.2 & 74 \\
0.08 & 79 & 0.3 & 71 \\
0.10 & 83 & 0.4 & 76 \\
0.12 & 85 & 0.5 & 77 \\
0.14 & 90 & 0.6 & 75 \\
0.16 & 87 & 0.7 & 74 \\
0.18 & 100 & 0.8 & 71 \\
& & 0.9 & 70 \\
Mean & 85 & Mean & 73 \\
\hline
\end{tabular}


therefore be obtained from a plot of $\ln \beta$ against $1 / T$ for a fixed degree of conversion since the slope of such a line is given. The apparent activation energies calculated form the slopes are tabulated in Table 8. The mean values of $E$ for oil shale and kerogen are 87 and $76 \mathrm{~kJ} / \mathrm{mol}$, respectively.

From the data in Tables 6,7 and 8 , it was found that the removal of mineral matter caused a decrease in the apparent activation energies of pyrolysis reactions of oil shale. It is probable that diffusion of the organic matter throughout the mineral matrix required a higher temperature and relatively more energy. This is in accordance with higher $\mathrm{T}_{\text {onset }}$ observed for original oil shale (Table 5). Apparent activation energies calculated for the pyrolysis reaction of isolated kerogen were lower than those of the original oil shale. In this respect, the values reported here are similar to those given in literature for oil shale [6, 28, 29]. Dembicki [30] examined the effect of various minerals on determination of kinetic parameters for source rock, by pyrolyzing mixtures of sedimentary minerals varying the concentration of kerogen isolated from Kimmeridgian black shale. The kinetic parameters derived indicated that added mineral matter such as quartz, calcite and dolomite shifted the value of apparent activation energy to higher values than those observed for the isolated kerogen.

Comparison with literature data shows that the kinetic parameters are unique to each individual type of oil shale. Olivella and Heras [31] used nonisothermal thermogravimetry to study kinetics of degradation of fossil fuels: the apparent activation energy of degradation of two oil shales from the Ribesalbes basin (Type I-S), calculated by the Friedman method, was found to be between 124 and $131 \mathrm{~kJ} / \mathrm{mol}$. Olivella and Heras [32] performed linear kinetic methods for pyrolysis of Spanish coals and oil shale and found mean values of apparent activation energies of Ribesalbes oil shale (Type I-S) to be between 195 and $286 \mathrm{~kJ} / \mathrm{mol}$.

Table 8. Apparent activation energies of oil shale and isolated kerogen obtained by Flynn-Wall-Ozawa method

\begin{tabular}{|c|c|c|c|}
\hline \multicolumn{2}{|c|}{ Oil shale } & \multicolumn{2}{|c|}{ Kerogen } \\
\hline $\mathrm{x}$ & $\begin{array}{c}\text { Activation energy, } \\
\mathrm{kJ} / \mathrm{mol}\end{array}$ & $\mathrm{x}$ & $\begin{array}{c}\text { Activation energy, } \\
\mathrm{kJ} / \mathrm{mol}\end{array}$ \\
\hline 0.04 & 104 & 0.1 & 72 \\
0.06 & 72 & 0.2 & 73 \\
0.08 & 69 & 0.3 & 76 \\
0.10 & 77 & 0.4 & 78 \\
0.12 & 87 & 0.5 & 76 \\
0.14 & 92 & 0.6 & 79 \\
0.16 & 89 & 0.7 & 74 \\
0.18 & 109 & 0.8 & 76 \\
& & 0.9 & 80 \\
Mean & 87 & Mean & 76 \\
\hline
\end{tabular}


Torrente and Galan [4] obtained apparent activation energy of $167 \mathrm{~kJ} / \mathrm{mol}$ for non-isothermal TGA of Puertollano (Spain) oil shale. Sonibare et al. [33] performed non-isothermal TGA on Lokpanta oil shales (Nigeria) and found the apparent activation energies to vary from 73.2 to $75 \mathrm{~kJ} / \mathrm{mol}$. Other researchers have reported similar values of apparent activation energies for the main stage of decomposition of oil shale organic matter. Skala et al. [34] performed non-isothermal TGA on Yugoslavian oil shales and found overall apparent activation energies to range from 42.9 to $114.7 \mathrm{~kJ} / \mathrm{mol}$. Dogan and Uysal [22], however, reported results for Turkish oil shale of approximately $25 \mathrm{~kJ} / \mathrm{mol}$ for the lower temperature decomposition and up to $43 \mathrm{~kJ} / \mathrm{mol}$ for the main stage of decomposition. Similarly, Jaber and Probert [7] reported apparent activation energies for the two-stage pyrolysis of Jordanian oil shales: $10 \mathrm{~kJ} / \mathrm{mol}$ in the low-temperature and $40-68 \mathrm{~kJ} / \mathrm{mol}$ in the hightemperature range.

The difference between the results determined in this study and those found by other workers is probably due to the fact that types of oil shale and routes of pyrolysis are different. The mathematical treatment of the TGA data may also influence the value of the quoted apparent activation energy. Also the type of kerogen in oil shale has been found to yield different values of apparent activation energies. Other factors include the size range of oil shale particles and the type and amount of mineral matter. The thermogravimetric analyser merely records overall weight loss. The decomposition of kerogen to oil represents a complex range of reactions, in series and parallel, and the extent to which each reaction becomes rate limiting under a particular set of experimental conditions may remain unresolved.

In order to find the kinetic model of thermal degradation, the Criado and Coats-Redfern methods were chosen as they involve the degradation mechanisms. The used models and the expressions of associated functions $g(x)$ and $f(x)$ are shown in Table 1. The master curve plots $Z(x) / Z(0.5)$ versus $x$ for different mechanisms according to the Criado method for oil shale and its kerogen degradation are illustrated in Figs. 5 and 6, respectively. Firstly, it shows that the experimental data for oil shale correspond to the diffusion (Dn) model. The comparison of the experimental master plots with theoretical ones revealed that the kinetics of degradation of isolated kerogen was most probably describable by the F1 and A4 models.

In order to determine the most probable model, the Coats-Redfern method was used. According to Eq. (8), apparent activation energy for every $g(x)$ function listed in Table 1 can be calculated at $10 \mathrm{~K} / \mathrm{min}$ from fitting $\ln g(x) / T^{2}$ versus $1 / T$ plots. The apparent activation energies and correlations at $10 \mathrm{~K} / \mathrm{min}$ are tabulated in Table 9 . To elucidate the degradation mechanism of oil shale and its kerogen, we have compared the apparent activation energies obtained by the methods above. According to Table 9, it could be found that the $E$ value of oil shale corresponding to the mechanism D4 is in good agreement with the value obtained by the 
KAS method $(80 \mathrm{~kJ} / \mathrm{mol})$. Otherwise, the mechanism of thermal degradation of kerogen agrees with the mechanism F1 according to which apparent activation energy is $66 \mathrm{~kJ} / \mathrm{mol}$, this value is in agreement with those obtained by the KAS method.

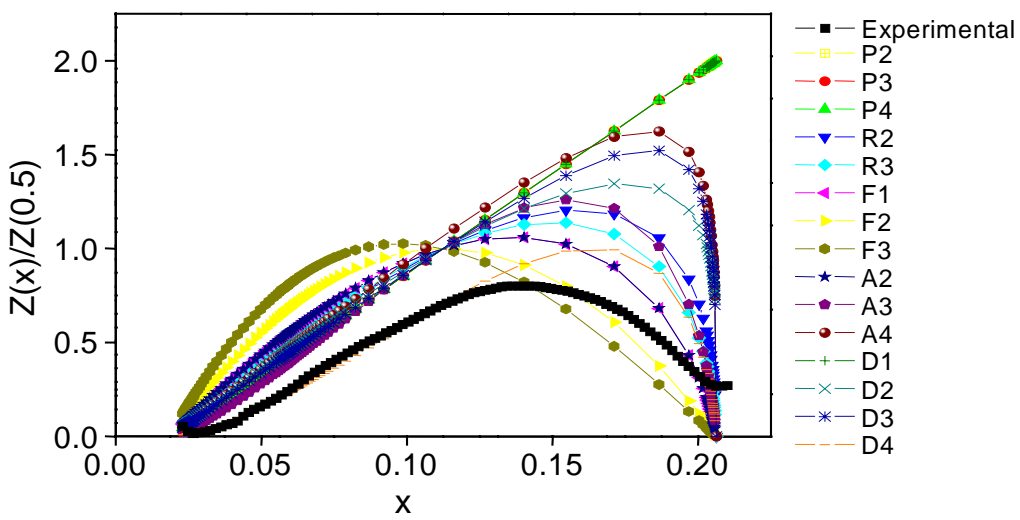

Fig. 5. Masterplots of different kinetic models and experimental data at $10 \mathrm{~K} / \mathrm{min}$ calculated by Eq. (13) for oil shale degradation.

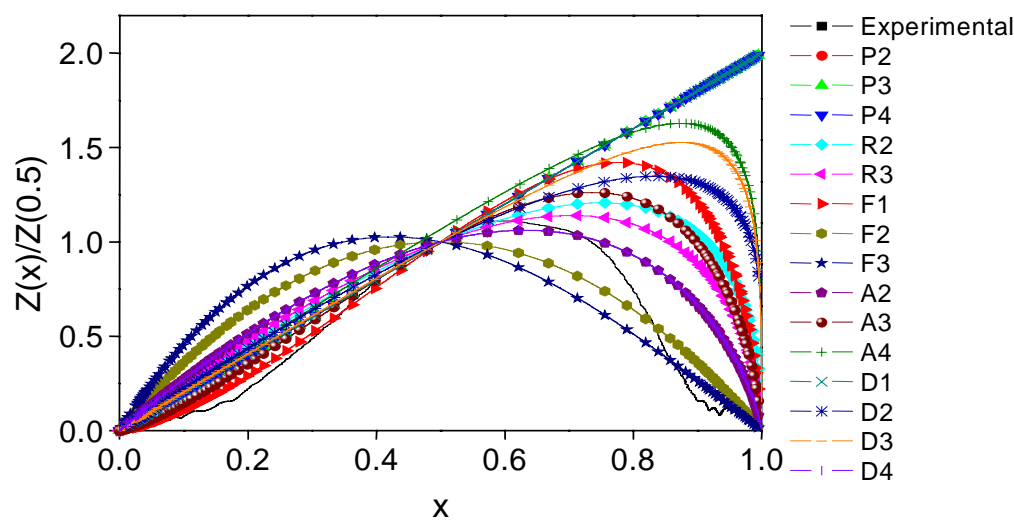

Fig. 6. Masterplots of different kinetic models and experimental data at $10 \mathrm{~K} / \mathrm{min}$ calculated by Eq. (13) for isolated kerogen degradation. 
Table 9. Apparent activation energies of oil shale and isolated kerogen obtained by Coats-Redfern method

\begin{tabular}{|c|c|c|c|c|}
\hline \multirow{2}{*}{ Model } & \multicolumn{2}{|c|}{ Oil shale } & \multicolumn{2}{c|}{ Kerogen } \\
\cline { 2 - 5 } & $\begin{array}{c}\text { Activation energy, } \\
\mathrm{kJ} / \mathrm{mol}\end{array}$ & $\begin{array}{c}\text { Correlation } \\
\text { coefficient, } \mathrm{r}\end{array}$ & $\begin{array}{c}\text { Activation energy, } \\
\mathrm{kJ} / \mathrm{mol}\end{array}$ & $\begin{array}{c}\text { Correlation } \\
\text { coefficient, } \mathrm{r}\end{array}$ \\
\hline P2 & 7 & 0.98631 & 14 & 0.99796 \\
P3 & 12 & 0.98835 & 9 & 0.99178 \\
P4 & 10 & 0.98741 & 7 & 0.99235 \\
A2 & 112 & 0.98867 & 26 & 0.99212 \\
A3 & 62 & 0.99371 & 40 & 0.99508 \\
A4 & 180 & 0.98856 & 46 & 0.99075 \\
R2 & 148 & 0.98873 & 50 & 0.99320 \\
R3 & 163 & 0.99112 & 52 & 0.99445 \\
D1 & 119 & 0.98984 & 96 & 0.98994 \\
D2 & 186 & 0.97869 & 102 & 0.99152 \\
D3 & 138 & 0.96120 & 117 & 0.99231 \\
D4 & 80 & 0.998675 & 111 & 0.99134 \\
F1 & 215 & 0.99212 & 66 & 0.99938 \\
F2 & 197 & 0.99134 & 113 & 0.99074 \\
F3 & 206 & 0.99032 & 185 & 0.99178 \\
\hline
\end{tabular}

\section{Conclusions}

An experimental study on thermal decomposition characteristics of Tarfaya oil shale and its kerogen samples is presented. The following conclusions were drawn from the research conducted:

- The decomposition process of Tarfaya oil shale involves three stages. The second stage (433-873 K) is the main mass loss stage, attributed to decomposition of the hydrocarbon material. At higher temperatures there was a significant mass loss due to decomposition of mineral compounds.

- There is a shift in the maximum rate of mass loss to higher temperatures with increasing heating rate.

- The results of kinetic analysis show that the most probable model for the pyrolysis process of oil shale organic matter agrees with the diffusion model (D4 mechanism), and the thermal degradation process of isolated kerogen goes to a mechanism involving a simple $n$-order model (F1 mechanism). The apparent activation energies of pyrolysis of the organic matter of oil shale and isolated kerogen were $80-87$ and $69-76 \mathrm{~kJ} / \mathrm{mol}$, respectively. A single kinetic expression is valid over the temperature range of kerogen pyrolysis between 433 and $873 \mathrm{~K}$. In addition, the results indicate that the removal of mineral matter affected the kinetics and mechanism of pyrolysis established for kerogen in the oil shale. 


\section{REFERENCES}

1. Nuttall, H. E., Guo, T. M., Schrader, S., Thakur, D. S. Pyrolysis kinetics of several key world oil shales // Geochemistry and Chemistry of Oil Shales / F. P. Miknis, J.F. McKay (Eds.). ACS Symposium Series 230, American Chemical Society, Washington, DC, 1983. P. 269.

2. Bekri, O., Ziyad, M. Synthesis of oil Shale R \& D Activities in Morocco. Proceedings of the 1991 Eastern Oil Shale Symposium, Lexington, Kentucky, 1991.

3. Rajeshwar, $K$. The kinetics of the thermal decomposition of Green River oilshale kerogen by non-isothermal thermogravimetry // Thermochim. Acta 1981. Vol. 45, No. 3. P. 253-263.

4. Torrente, M. C., Galan, M. A. Kinetics of the thermal decomposition of oil shale from Puertollano (Spain) // Fuel. 2001. Vol. 80, No. 3. P. 327-334.

5. Kok, M. V. Thermal investigation of Seyitomer oil shale // Thermochim. Acta. 2001. Vol. 369, No. 1-2. P. 149-155.

6. Karabakan, A., Yurum, Y. Effect of the mineral matrix in the reactions of oil shales: 1. Pyrolysis reactions of Turkish Göynük and US Green River oil shales // Fuel. 1998. Vol. 77, No. 12. P. 1303-1309.

7. Jaber, J. O., Probert, S. D. Non-isothermal thermogravimetry and decomposition kinetics of two Jordanian oil shales under different processing conditions // Fuel Process. Technol. 2000. Vol. 63, No. 1. P. 57-70.

8. Williams, P. T., Ahmad, N. Investigation of oil-shale pyrolysis processing conditions using thermogravimetric analysis // Appl. Energy. 2000. Vol. 66, No. 2. P. 113-133.

9. Kissinger, H. E. Reaction kinetics in differential thermal analysis // Anal. Chem. 1957. Vol. 29, No. 11. P. 1702-1706.

10. Akahira, T., Sunose, T. Trans. Joint Convention of Four Electrical Institutes, Paper No. 246, 1969 Research Report // Chiba Institute of Technology Sci. Technol. 1971. Vol. 16. P. 22-31.

11. Coats, A. W., Redfern, J. P. Kinetic parameters from thermogravimetric data // Nature. 1964. Vol. 201. P. 68-69.

12. Friedman, $H$. Kinetics of thermal degradation of char-forming plastics from thermogravimetry. Application to a phenolic plastic // J. Polym. Sci., Part C. 1964. Vol. 6. P. 183-195.

13. Flynn, J. H., Wall, L. A. A quick, direct method for the determination of activation energy from thermogravimetric data // Polym. Lett. 1966. Vol. 4. P. 323-328.

14. Ozawa, T. A new method of analyzing thermogravimetric data// Bull. Chem. Soc. Jpn. 1965. Vol. 38, No. 11. P. 1881-1886.

15. Doyle, $C$. Kinetic analysis of thermogravimetric data // J. Appl. Polym. Sci. 1961. Vol. 5, No. 15. P. 285-292.

16. Criado, J. M. Kinetic analysis of DTG data from master curves // Termochim. Acta. 1978. Vol. 24, No. 1. P. 186-189.

17. Bouchta, R. Valorization studies of the Moroccan [sic] oil shales. - Office Nationale de Researches et Exploitations Pétrolières B. P. 774, Agdal, Rabat, Maroc, 1984. 
18. Wang Qing, Bai Jingru, Sun Baizhong, Sun Jian. Comprehensive utilization strategy of Huandian oil shale instead of strategy of Huadian oil shale comprehensive utilization // Oil Shale. 2005. Vol. 22, No. 3. P. 305-316.

19. Jaber, J. O., Probert, S. D. Pyrolysis and gasification kinetics of Jordanian oil shales // Appl. Energy. 1999. Vol. 63, No. 4. P. 269-286.

20. Wang Qing, Sun Baizhong, Hu Aijuan, Bai Jingru, Li Shaohua. Pyrolysis characteristics of Huadian oil shales // Oil Shale. 2007. Vol. 24, No. 2. P. 147157.

21. Williams, P. T., Ahmad, N. Influence of process conditions on the pyrolysis of Pakistani oil shales // Fuel. 1999. Vol. 78, No. 6. P. 653-662.

22. Dogan, O. M, Uysal, B. Z. Non-isothermal pyrolysis kinetics of three Turkish oil shales // Fuel. 1996. Vol. 75, No. 12. P. 1424-1428.

23. Williams, P.F.V. Thermogravimetry and decomposition kinetics of British Kimmeridge clay oil shale // Fuel. 1985. Vol. 64, No. 4. P. 540-545.

24. Burnham, A. K., Happe, J. A. On the mechanism of kerogen pyrolysis // Fuel. 1984. Vol. 63, No. 10. P. 1353-1356.

25. Gersten, J., Fainberg, V., Hetsroni, A., Shindler, Y. Kinetic study of the thermal decomposition of polypropylene, oil shale, and their mixture // Fuel. 2000. Vol. 79, No. 13. P. 1679-1686.

26. Rajeshwar, K. Thermal analysis of coal, oil shales and oil sands // Thermochim. Acta. 1983. Vol. 63, No. 1. P. 97-112.

27. Thakur, D. S., Nuttall, H.E. Kinetics of pyrolysis of Moroccan oil-shale by thermogravimetry // Ind. Eng. Chem. Res. 1987. Vol. 26, No. 7. P. 1351-1356.

28. Skala,D., Kopsch, H., Sokič, M., Neumann, H.-J., Jovanovič, J. A. Thermogravimetrically and differential scanning calorimetrically derived kinetics of oil shale pyrolysis // Fuel. 1987. Vol. 66, No. 9. P. 1185-1191.

29. Ballice, L., Yüksel, M., Saglam, M., Schulz, H., Hanoglu, C. Application of infrared spectroscopy to the classification of kerogen types and the thermogravimetrically derived pyrolysis kinetics of oil shales // Fuel. 1995. Vol. 74, No. 11. P. 1618-1623.

30. Dembicki, H.J. The effects of the mineral matrix on the determination of kinetic parameters using modified Rock Eval pyrolysis // Org. Geochem. 1992. Vol. 18, No. 4. P. 531-539.

31. Olivella, M. A., De Las Heras, $F . X$. C. Nonisothermal thermogravimetry of Spanish fossil fuels // Oil Shale. 2006. Vol. 23, No. 4. P. 340-355.

32. Olivella, M. A., De Las Heras, F. X. C. Evaluation of linear kinetic methods from pyrolysis data of Spanish oil shales and coals // Oil Shale. 2008. Vol. 25, No. 2. P. 227-245.

33. Sonibare, O. O., Ehinola, O. A., Egashira, R. Thermal and geochemical characterization of Lokpanta oil shales, Nigeria // Energy Convers. Manage. 2005. Vol. 46, No. 15-16. P. 2335-2344.

34. Skala, D., Sokic, M., Kopsch, H. Oil shale pyrolysis - a new approach to the kinetic investigation of different kerogen type samples // Thermochim. Acta. 1988. Vol. 134. P. 353-358. 